\title{
Optimal System Parameters and Hybrid Ratio for Fuel Cell Hybrid Electric Vehicles
}

\author{
Lailian Feng, ${ }^{1,2}$ Ting-Cheng Chang, ${ }^{1 *}$ Guo Weiwei, ${ }^{2}$ \\ Yi-Chun Xie, ${ }^{2}$ and Li-Ping Zheng ${ }^{2}$ \\ ${ }^{1}$ Department of Information, Mechanical and Electrical Engineering, Ningde Normal University, \\ Xueyuan Road No. 1, Fujian, Ningde 352100, China \\ ${ }^{2}$ Fujian Fuan Mindong Yanan Electrical Machine Co., Ltd., Fuan 355000, China
}

(Received October 22, 2019; accepted April 24, 2020)

Keywords: fuel cells, rechargeable battery, hybrid power, optimal hybrid ratio

Fuel cells are eco-friendly energy devices with high efficiency. They are regarded as ideal power sources, especially for hybrid vehicles with rechargeable batteries. In this study, we proposed the parameters for the optimal hybrid ratio of a fuel cell hybrid electric vehicle (FCHEV). We made a model FCHEV with fuel cells and rechargeable batteries (Li-ion batteries) and carried out various tests to obtain parameters for several driving conditions. These parameters are used to find the optimal ratio of the power of the fuel cells to the total power (power of fuel cells + power of rechargeable batteries). The results indicate that the optimal hybrid ratio is 0.4 . In this case, the powers from the fuel cells and rechargeable batteries are about 50 and $70 \mathrm{~kW}$, respectively. The optimal parameters in this study can be used to develop power transmission systems of FCHEVs. The results of this study are expected to improve FCHEVs to become an important means of mass transportation.

\section{Introduction}

As the emission of pollutants from vehicles is regarded as a significant source of air pollution, electric vehicles (EVs) are becoming important countermeasures. ${ }^{(1)}$ EVs are grouped into several categories depending on the power source: battery electric vehicles (BEVs), hybrid electric vehicles (HEVs), plug-in hybrid electric vehicles (PHEVs), and fuel cell electric vehicles (FCEVs). China has stressed the necessity of EVs, prioritizing the development of FCEVs in its National 863 Program and 12th Five-Year Economy Plan. ${ }^{(2-7)}$ The development of EVs has brought about a boom in related $\mathrm{R} \& \mathrm{D}$, in which sensor technologies play an important role. This is because EVs require sensing technologies for current and voltage detection, battery temperature monitoring, and so forth.

Among the EVs, FCEVs are considered to have made a significant contribution to the development of eco-friendly vehicles. ${ }^{(8-13)}$ FCEVs use hydrogen as their fuel, which is regarded as an ideal fuel for EVs with high efficiency and the emission of no pollutants; the only direct emissions are water and heat. However, fuel cells have some drawbacks, such as safety, high

*Corresponding author: e-mail: 18250922163@163.com

https://doi.org/10.18494/SAM.2020.2694 
production and management costs, low power at low temperatures, and insufficient reserve capacity. ${ }^{(14,15)}$ The safety can be improved by adopting high-performance hydrogen sensors, which can even improve fuel economy, ${ }^{(16)}$ while the other problems can be overcome by employing an auxiliary power source such as rechargeable batteries.

Fuel cells and rechargeable batteries can act as complementary sources of power, with the fuel cells compensating for the low energy density and long recharge time of rechargeable batteries. For fuel cell hybrid electric vehicles (FCHEVs), various types of rechargeable batteries such as Ni-MH, lead acid, and lithium-ion batteries are adopted as auxiliary power sources. The "peak-load shifting" of high-performance rechargeable batteries working with fuel cells can enable FCHEVs to maintain efficient power management. This can improve the efficiency and dynamics of the power source. ${ }^{(17)}$

However, the efficient management of two independent power systems is the most critical problem for FCHEVs owing to the complex system with multiple components. This is a hurdle in using FCHEVs as a means of transportation. With this background, we designed and developed a model FCHEV (a bus) to find an efficient power management strategy. Then, we computed the parameters of the power system to find an appropriate energy management strategy by investigating the power-follow control of the FCHEV. With the ADVISOR vehicle simulator, we calculated the optimal parameters for the energy management of the FCHEV, then the optimal hybrid ratio of the power from the fuel cells to the total power from the fuel cells and rechargeable batteries. The results can be applied to FCHEVs, especially to buses to increase their use for mass transportation.

\section{Parameters of Power System of FCHEV}

The system structure of the FCHEV is presented in Fig. 1. The prototype FCHEV adopts an electric motor named "Golden Dragon Coasters". The specifications of the FCHEV are a total mass of $7500 \mathrm{~kg}(\mathrm{~m})$, a rolling resistance coefficient of 0.012 , an aerodynamic drag factor of $0.6\left(C_{D}\right)$,

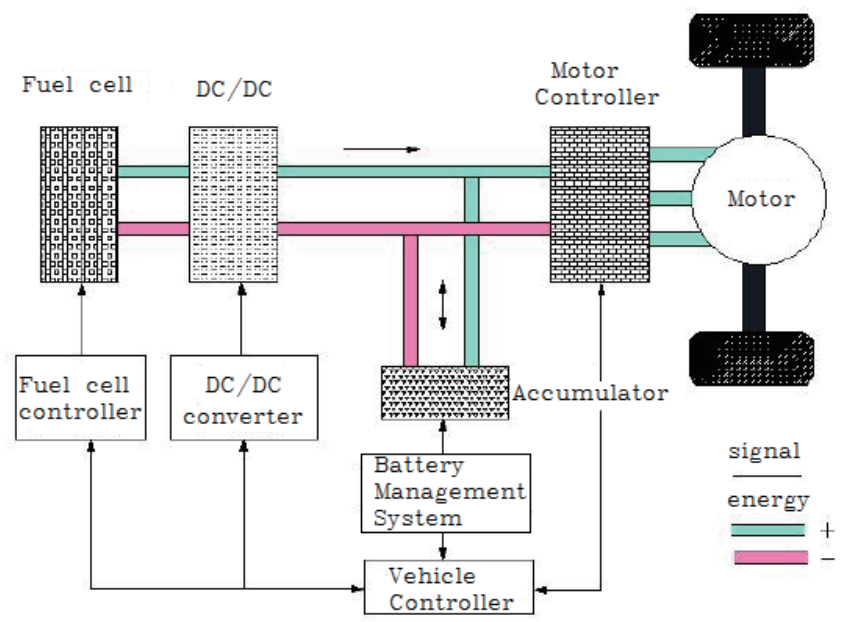

Fig. 1. (Color online) Structure of the hybrid power system of the FCHEV in this study. 
a frontal area of $5.4 \mathrm{~m}^{2}(A)$, a driving wheel radius of $0.303 \mathrm{~m}(R)$, an efficiency of 0.85 for the drive system, and a wheelbase of $3.935 \mathrm{~m}$.

\subsection{Calculation of motor data}

The motor of the drive system and its controller are critical parts of an FCHEV, which comprises an electric motor, a power converter, a controller, various detecting sensors, and rechargeable batteries. The drive system of an FCHEV transfers electrical power to the wheels, converting it to kinetic energy. Electrical energy can be regenerated from the rotating wheels and deceleration. When the FCHEV decelerates, the fuel cells are turned off, and the motor acts as a generator to charge the batteries.

There are several requirements for motors in FCEVs. First, their operating properties should be compatible with various driving situations such as starting, climbing, and highspeed driving. In addition, the motors should have a sufficient overload capacity, a satisfactory starting performance, a long service life, a superior reliability, and a low price. Dustproofing and waterproofing are also important for the motors.

The main parameters of a drive motor's performance are motor power, torque, and rotational speed. Here, the rotational speed is determined by the specific acceleration ability, climbing performance, and maximum speed of the vehicle. We calculated these parameters as follows.

\subsubsection{Selection of drive motor power}

Rated power and peak power are essential parameters of a drive motor. The motor power of EVs is generally determined by the maximum speed and climbing gradient.

(1) Motor power calculated from maximum speed

When an FCEV runs at a high velocity constantly on a flat road with zero slope resistance and zero acceleration resistance, the motor power can be obtained from the following basic power equation:

$$
P_{\max 1}=\frac{1}{\eta_{T}}\left(\frac{m g f}{3600} v_{\max }+\frac{C_{D} A}{76140} v_{\max }^{3}\right)
$$

Here, $P_{\max 1}=80 \mathrm{~kW}$ is obtained by substituting the parameters of the model vehicle.

(2) Motor power calculated from climbing gradient

When an EV is climbing up a road with a certain gradient at a speed of $v_{a}=20 \mathrm{~km} / \mathrm{h}$ with zero acceleration resistance, the consumed power is expressed as

$$
P_{\max 2}=\frac{1}{\eta_{T}}\left(\frac{m g f \cos \alpha}{3600} v_{a}+\frac{C_{D} A}{76140} v_{a}^{3}+\frac{m g f \sin \alpha}{3600} v_{a}\right)
$$

$P_{\max 2}=114 \mathrm{~kW}$ is obtained by substituting the parameters of the model vehicle. 
When the motor power of the FCHEV meets the requirements of the maximum speed and climbing gradient, the peak power of its motor is

$$
P_{m}=\max \left\{P_{\max 1}, P_{\max 2}\right\}
$$

Then, setting $120 \mathrm{~kW}$ as the peak power $P_{m}$, the rated power of the motor is calculated as

$$
P_{e}=\frac{P_{m}}{\lambda}
$$

where $P_{e}$ is the rated power of the motor in $\mathrm{kW}$ and $\lambda$ is the overload factor of the motor, which is generally $2-3 . P_{e}$ is $60 \mathrm{~kW}$ in this study.

\subsubsection{Determination of torque of drive motor}

A drive motor transmits torque directly to the wheels. The size of the wheels affects the acceleration and climbing ability of FCEVs. However, to guarantee that a vehicle has sufficient acceleration power and climbing torque, it is necessary to select torque parameters of the motor mainly on the basis of the required climbing ability. Assuming that the effects of acceleration and air resistances are negligible during climbing, the torque equation of the vehicle can be simplified to

$$
\frac{T_{t q} i_{g} i_{0} \eta_{T}}{r}=G f+G i
$$

Using the above equation, the climbing torque is calculated as

$$
T_{m}=\frac{m g f \cos \left(\arctan \left(\frac{\alpha}{100}\right)\right)}{i_{g} i_{0} \eta_{T}}+\frac{m g \sin \left(\arctan \left(\frac{\alpha}{100}\right)\right) r}{i_{g} i_{0} \eta_{T}} .
$$

When the vehicle is decelerated with the main reducing gear of the FCHEV and the speed changer is omitted, $T_{m}$ is 1 . In a previous study, ${ }^{(18)}$ when the speed-reducing ratio was selected as 4.5, the maximum torque was obtained as $706 \mathrm{~N} \cdot \mathrm{m}$ using Eq. (6). In this study, the maximum torque of the drive motor is set as $710 \mathrm{~N} \cdot \mathrm{m}$, and the rated torque of the motor is half of its maximum torque, $355 \mathrm{~N} \cdot \mathrm{m}$.

\subsubsection{Selection of drive motor speed}

The rotational speed of a drive motor directly affects the running performance of a vehicle. When the rated power is constant, the rotational speed is inversely proportional to the torque. 
That is, the lower the rated speed, the larger the corresponding rated torque of the motor. Thus, to ensure the sufficient starting acceleration and stable running of a vehicle, it is necessary to place a limit on the rated speed of the motor. The relationship between the running speed and transmission ratio of a vehicle is

$$
v=0.337 \frac{n r}{i_{g} i_{0}} .
$$

When the designed maximum running speed of a vehicle is $100 \mathrm{~km} / \mathrm{h}$, to achieve the maximum running speed, the maximum rotational speed of the motor should be

$$
n_{\max }=\frac{v_{\max } i_{0} i_{g}}{0.337 r}
$$

By substituting the relevant parameters, the maximum rotational speed of the motor is calculated to be $4000 \mathrm{r} / \mathrm{min}$. By substituting

$$
P_{e}=\frac{T_{t q} n_{e}}{9550}
$$

into Eq. (8), the drive motor speed is obtained as $1600 \mathrm{r} / \mathrm{min}$.

The selected parameters of the AC motor are summarized as follows: the rated power is $60 \mathrm{~kW}$, the maximum power is $120 \mathrm{~kW}$, the rated torque is $355 \mathrm{~N} \cdot \mathrm{m}$, the maximum torque is $710 \mathrm{~N} \cdot \mathrm{m}$, the maximum speed is $4000 \mathrm{r} / \mathrm{min}$, and the rated speed is $1600 \mathrm{r} / \mathrm{min}$.

\subsection{Selection of fuel cells}

\subsubsection{Structure and principle of fuel cells}

As the primary power source, fuel cells provide power for FCHEVs. Therefore, the selection of appropriate fuel cells is of vital importance to ensure a satisfactory performance. A schematic diagram of the system of fuel cells for FCHEVs is shown in Fig. 2 (the dashed lines show the path of recycled gas). ${ }^{(8)}$

\subsubsection{Selection of fuel cells for model vehicle}

Fuel cells have been developed over the last few decades. A proton exchange membrane fuel cell (PEM FC) has a compact, lightweight, and corrosion-resistant structure with high efficiency and high specific power. It does not emit any carbon dioxide and has broad applicability. The most significant advantage of the PEM FC is that it can operate even at room temperature, though its optimal temperature range for operation is $80-90{ }^{\circ} \mathrm{C}$. Therefore, PEM FCs are 


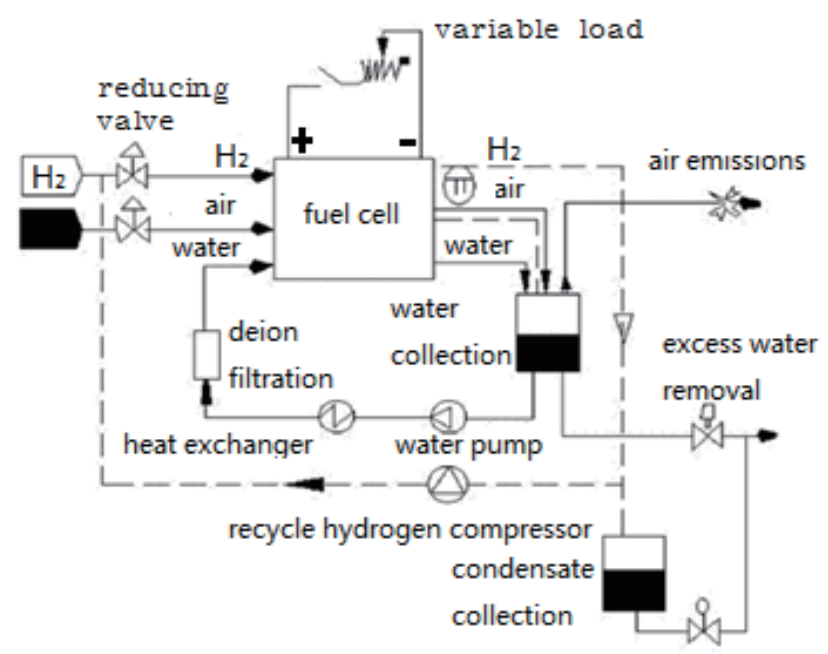

Fig. 2. Schematic diagram of the system of fuel cells in FCHEVs.

suitable power sources of FCEVs. Moreover, as the PEM is a proton-conducting polymer, no compression or decompression process is required. A PEM FC is composed of a fuel feeding/circulation system, an oxidant feed system, a power generating system, a water/thermal management system, a power system, and a security system.

Because of their advantages, we use PEM FCs as the main power source for the model vehicle. The theoretical energy efficiency of a PEM FC stack is nearly $83 \%$, but the real energy efficiency is estimated to be 50-60\%. The energy consumption distribution of NECAR 4 (the DaimlerChrysler FCEV) tested on a roller bench under the New European Driving Condition (NEDC) is shown in Fig. 3.

Figure 3 shows that the accessories of fuel cells and the vehicle itself also consume energy. Here, the system efficiency is defined as the net drive energy obtained by the drive wheels relative to the total energy generated by the fuel cells. Because traditional combustion engines usually operate under low-load working conditions, their efficiency is generally low. In contrast, the system efficiency of a PEM FC is high even under a low load. The efficiency curves for both a traditional internal combustion engine and a PEM FC are shown in Fig. $4 .^{(18)}$

\subsubsection{Parameter design of fuel cells}

The peak power is the maximum power within a short period of time with limited energy. When an FCEV constantly runs at a high speed for a certain distance, it must be guaranteed that the fuel cells supply sufficient electrical power for the FCEV to climb up slopes even without using the peak power.

The power $P_{f}$ of fuel cells is expressed as

$$
P_{f}=\frac{\frac{P_{e}}{\eta_{i n v}}+P_{a c c}}{\eta_{d c}},
$$




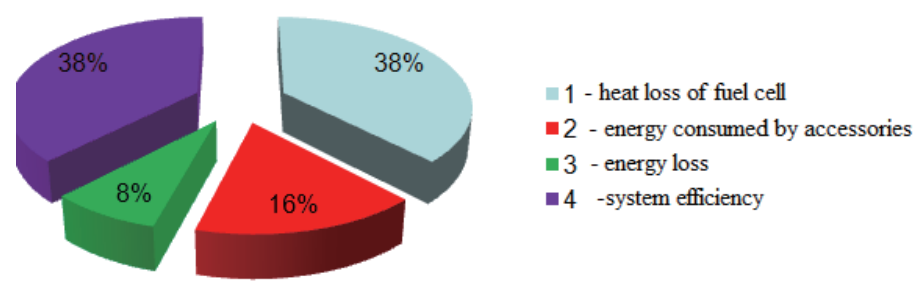

Fig. 3. (Color online) Energy consumption of NECAR 4.

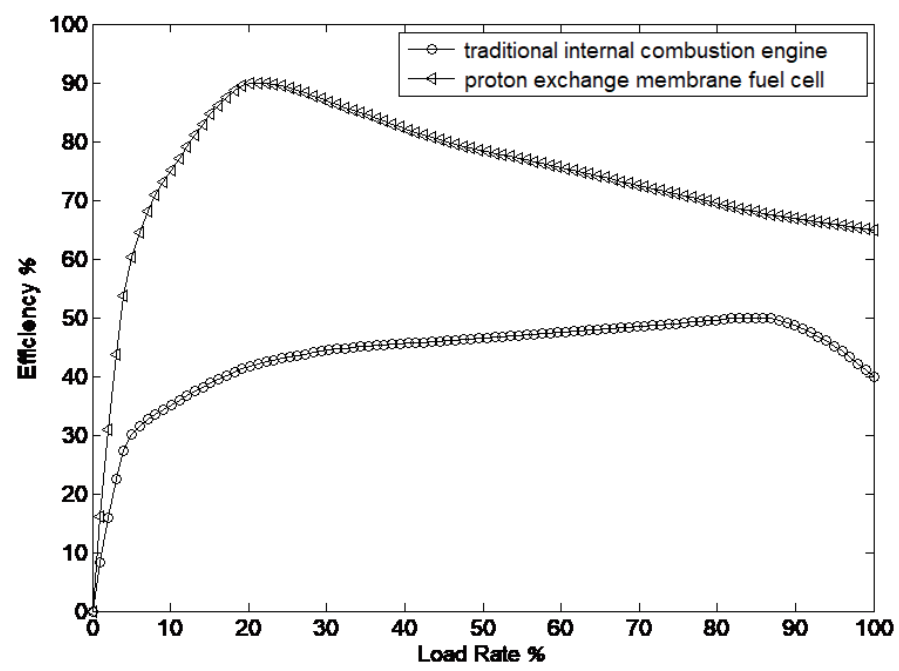

Fig. 4. Efficiency-load rate curves of internal combustion engine and PEM FC.

where $P_{e}$ is the rated power of the drive motor, $\eta_{i n v}$ is the efficiency of the inverter $(0.95), \eta_{d c}$ is the efficiency of the DC/DC converter (0.95), and $P_{a c c}$ is the power of the accessory equipment. Setting $P_{a c c}$ as $3 \mathrm{~kW}, P_{f}$ is $70 \mathrm{~kW}$.

\subsection{Selection of a battery system and its parameter design}

Using rechargeable batteries as the auxiliary power source of the model vehicle in this study enables a longer driving range. Power from the batteries contributes to the drive power of the vehicle and helps fuel cells operate stably in the case of insufficient power for starting, climbing, and accelerating. ${ }^{(10,11)}$ The rechargeable batteries can also store the excess energy of the power system when the drive power is smaller than the power generated from the fuel cells and during the deceleration of the vehicle.

\subsubsection{Selection of rechargeable battery}

Rechargeable batteries for EVs and HEVs must have a high energy density and a high power output. Different types of batteries have different performance characteristics depending on the 
electrical, mechanical, sealing, and storage properties. They may also have different shapes. Here, we describe two important properties: electrical and storage properties.

The electrical property of a rechargeable battery is determined by the charge-discharge voltage, internal resistance, capacity, specific characteristics, and service life, while the storage property is determined by the storage life and self-discharge. Table 1 shows the performance characteristics of several types of rechargeable batteries commonly used in EVs.

EVs mainly adopt Li-ion batteries, which have highly electronegative Li electrodes. The high average voltage of $3.2 \mathrm{~V}$ for a single Li-ion battery cell reduces the number of batteries required in a battery assembly for EVs. The charging efficiency of Li-ion batteries is higher than that of other batteries, but the self-discharge is $5-10 \%$ lower. They have a high storage stability with negligible chemical reactions occurring during idle times. Their ease of installment and compatibility with various technology applications also make Li-ion batteries an ideal auxiliary power source of FCHEVs.

\subsubsection{Determination of battery parameters}

According to the above analysis, fuel cells and rechargeable batteries together can provide the maximum power required for FCHEVs. The maximum output power of the rechargeable batteries must be greater than or equal to the difference between the maximum power of the drive motor and the maximum power of fuel cells,

$$
P_{\max } \geq P_{m}-P_{f}
$$

where $P_{\max }$ is the maximum power of the rechargeable batteries, $P_{m}$ is the power of the drive motor, and $P_{f}$ is the power of the fuel cells.

The Li-ion battery used in this study has a capacity of $100 \mathrm{Ah}$, a voltage of $3.2 \mathrm{~V}$ (for a single battery cell), and a maximum output power of a single cell of $0.8 \mathrm{~kW}$. As the total output power of the rechargeable batteries must be greater than or equal to the maximum power consumption of the FCHEV to guarantee stable driving, the required number of battery cells is

Table 1

Comparison of cell performance characteristics. ${ }^{(12)}$

\begin{tabular}{lccccccc}
\hline Type & Advantages & Disadvantages & \multicolumn{2}{c}{ Energy density } & Power density & $\begin{array}{c}\text { Service life / } \\
\text { recharge cycles }\end{array}$ & Cost \\
\hline $\begin{array}{l}\text { Sealed lead } \\
\text { acid }\end{array}$ & $\begin{array}{c}\text { High power } \\
\text { density, safe }\end{array}$ & $\begin{array}{c}\text { Low energy } \\
\text { density }\end{array}$ & 35 & 80 & 200 & $400-800$ & Low \\
\hline $\begin{array}{l}\text { Nickel- } \\
\text { hydrogen }\end{array}$ & $\begin{array}{c}\text { High power and } \\
\text { energy density }\end{array}$ & $\begin{array}{c}\text { High cost, poor } \\
\text { temperature } \\
\text { characteristic }\end{array}$ & 65 & 155 & 200 & $600-1200$ & High \\
\hline Nickel-zinc & $\begin{array}{c}\text { High power and } \\
\text { energy density }\end{array}$ & Low life service & 70 & 130 & 200 & $300-400$ & High \\
\hline Lithium-ion & $\begin{array}{c}\text { High voltage, high } \\
\text { energy density }\end{array}$ & High cost & 110 & 160 & 200 & 500 & Very high \\
\hline
\end{tabular}




$$
n_{1}=\frac{P_{\max }}{P_{b \max } \eta_{e} \eta_{e c}}
$$

where $P_{b \max }$ is the maximum output power of a single cell, $\eta_{e}$ is the working efficiency of the motor, and $\eta_{e c}$ is the working efficiency of the motor controller. The results of parameter estimation by the above calculation are summarized in Table 2 .

\section{Simulation Results and Analysis}

\subsection{Matching parameter verification of FCHEV}

The performance of the FCHEV in this study can be estimated from dynamic parameters and an economic parameter. The dynamic parameters include maximum speed, acceleration time, and climbing capacity, which are the same for internal combustion engine vehicles. In contrast, the economic parameter refers to a conversion factor from power consumption and hydrogen consumption per $100 \mathrm{~km}$.

We selected values of these parameters for the FCHEV in this study and used them to carry out a simulation with the ADVISOR simulator and Matlab/Simulink software. We input various values of the parameters in the simulations on ADVISOR, and then conducted dynamic and economic simulations of the model FCHEV.

Through this evaluation, a vehicle's performance can be assessed with an index obtained from the maximum speed, acceleration time, and climbing ability in accordance with international standards. The analysis of dynamic automobile performance is performed under the Urban Dynamometer Driving Schedule (UDDS) test.

The simulation results are shown in Fig. 5. The travel speed under the UDDS test is the same as the actual speed (both curves almost coincide) as shown in Fig. 5. It is clear that the power performance meets the requirements for urban road conditions. The result of the acceleration test shows that the maximum grade ability is $19.1 \%$ at $20 \mathrm{~km} / \mathrm{h}$. When the model vehicle drives at its highest speed of $127.4 \mathrm{~km} / \mathrm{h}$, the dynamic requirement of the model vehicle in this study is satisfied.

Table 2

System parameters.

\begin{tabular}{lccc}
\hline \multicolumn{3}{c}{ AC motor } \\
\hline Peak power capacity & $120 \mathrm{~kW}$ & Rated power & $60 \mathrm{~kW}$ \\
Peak torque & $710 \mathrm{~N} \cdot \mathrm{m}$ & Rated torque & $355 \mathrm{~N} \cdot \mathrm{m}$ \\
Maximum RPM & $4000 \mathrm{r} / \mathrm{min}$ & Rated RPM & $1600 \mathrm{r} / \mathrm{min}$ \\
Voltage & $380 \mathrm{~V}$ & Weight & $380 \mathrm{~kg}$ \\
\hline \multicolumn{4}{c}{ Fuel cell } \\
\hline Power & $70 \mathrm{~kW}$ & Output voltage \\
\hline \multicolumn{4}{c}{ Li-ion battery } \\
\hline Single voltage & $3.2 \mathrm{~V}$ & Capacity & $380 \mathrm{~V}$ \\
Number of batteries & 78 & Specific energy & $100 \mathrm{Ah}$ \\
\hline
\end{tabular}


Figure 5 also shows that the fuel consumption of the simulated model under the UDDS test is $93.3 \times 10^{-2} \mathrm{~L} / \mathrm{km}$, which is equivalent to the fuel consumption of about $6.3 \times 10^{-2} \mathrm{~L} / \mathrm{km}$ for a vehicle with a traditional internal combustion engine. This result means that the model vehicle has excellent fuel efficiency. The direct emission of the model vehicle is zero. The initial value of the state of charge (SOC) is set as 0.7. The difference in the SOC of the rechargeable batteries before and after the circulation is 0 . It can be seen that the SOC of the rechargeable batteries drops at the start of the operation of the model vehicle to provide sufficient power for the drive system. This means that the problem of a slow start is solved for the FCHEV. Then, the fuel cells provide excess power to the electric generator to recharge the batteries. At 1200 $\mathrm{s}$, the SOC of the rechargeable batteries reaches 0.8 , suggesting that the optimal upper limit of the SOC is 0.8 in accordance with the control strategy. The SOC always fluctuates between the initially set value of 0.7 and the optimal upper limit of 0.8 .

\subsection{Variation of fuel efficiency with hybrid ratio}

Guezennec et al. addressed the benefits of the hybridization of FCEVs. ${ }^{(19)}$ These benefits are efficiency gains and a significant loosening of the dynamic control requirements for automotive fuel cell systems. However, they did not study the relationship between hybrid ratio and economy. Kim and Peng formulated combined power management/design optimization for the performance optimization of FCHEVs. ${ }^{(20)}$ Its processes included subsystem-scaling models to predict the characteristics of components of different sizes. They also designed a parameterizable and near-optimal controller for the power management optimization. This controller, which was inspired by their stochastic dynamic programming results, can be included

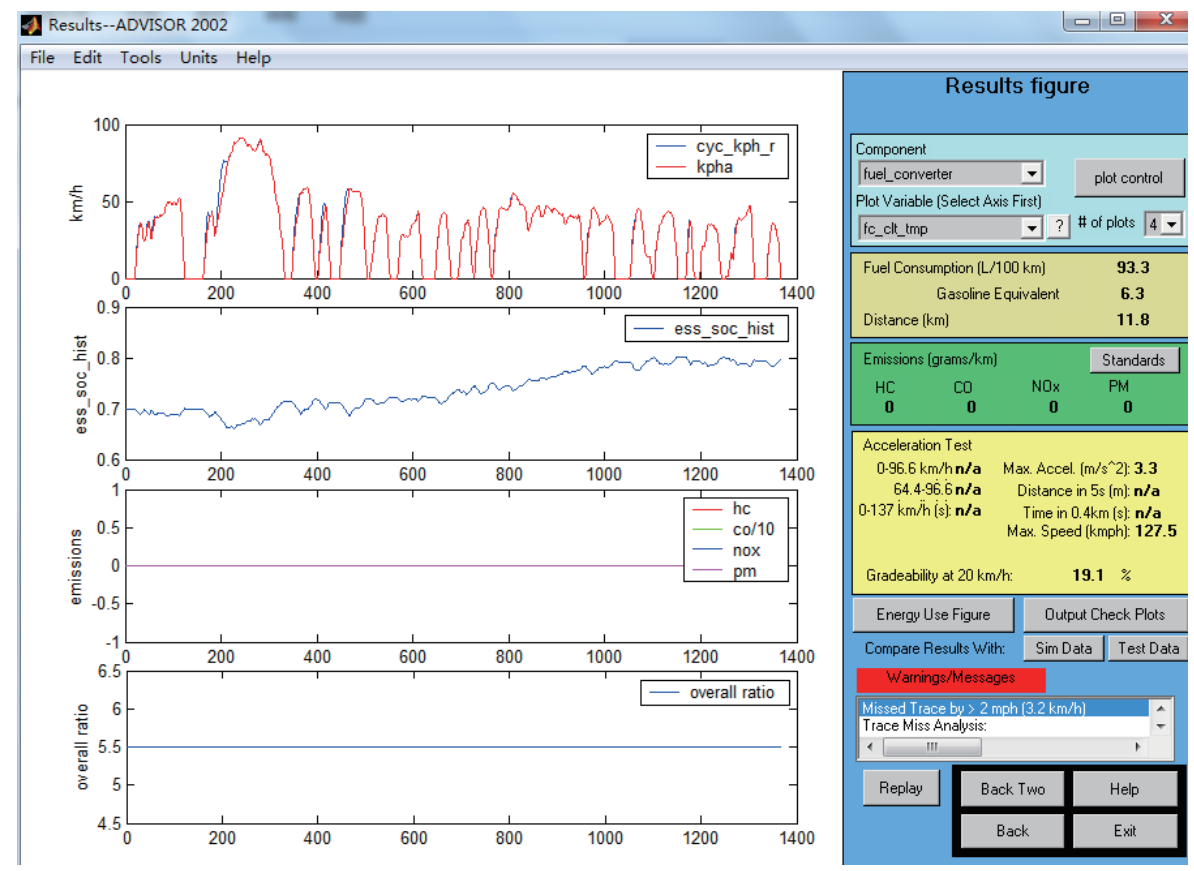

Fig. 5. (Color online) Interface showing simulation results. 
for the system optimization. Simulation results demonstrate that combined optimization can efficiently provide excellent fuel economy. Atwood et al. have studied the fuel economy of electric-electric hybrid fuel cell vehicles under several different operating conditions and hybrid ratios. ${ }^{(21)}$ However, they did not focus on the effects of changes in power system quality and cost factor. Tao et al. took the hybrid ratio of a fuel cell/battery HEV as the research focus and analyzed the mechanisms by which the hybrid ratio affects the fuel economy through simulation and calculation in ADVISOR to give related general design rules. ${ }^{(22)}$

The above studies only considered fuel economy, while this study deals with the relationship between hybrid ratio, fuel economy, and vehicle power. Thus, our model design is considered to be more reasonable and to give more practical results.

When the power of the fuel cells is less than $30 \mathrm{~kW}$, FCHEVs are driven at a low speed only by the fuel cells. When the drive conditions change, the fuel cells and rechargeable batteries must start and stop frequently. This lowers the working efficiency of the system and reduces the service life of the rechargeable batteries, increasing the maintenance cost of the vehicle. Thus, the model vehicle in this study does not have any practical significance for a hybridization degree (i.e., the ratio of the fuel cell power to the total power) lower than $25 \%$. When the power of the fuel cells is greater than $30 \mathrm{~kW}$, four different working modes are selected for the simulation as follows:

(1) NEDC: New European Driving Cycle, characterized by a low engine load, a low exhaust gas temperature, and a maximum speed of $50 \mathrm{~km} / \mathrm{h} .{ }^{(23)}$

(2) UDDS: Urban Dynamometer Driving Schedule, the test for an urban route of $12.07 \mathrm{~km}$ with frequent stops. The maximum speed is $91.2 \mathrm{~km} / \mathrm{h}$ and the average speed is $31.5 \mathrm{~km} / \mathrm{h}$. This schedule has two phases, a "cold start" phase of $505 \mathrm{~s}$ over a projected distance of $5.78 \mathrm{~km}$ at an average speed of $41.2 \mathrm{~km} / \mathrm{h}$ and a "transient phase" of $864 \mathrm{~s}$, giving a total duration of $1369 \mathrm{s.}^{(24)}$

(3) HWEFT: The Highway Fuel Economy Test, which is the highway fuel economy rating, while the city rating is based on the UDDS test. ${ }^{(25)}$

(4) CONSTANT_60: the fuel economy test mode of China's urban roads.

Simulation results and a comparison of the efficiencies obtained at different hybrid ratios under these four running modes are summarized in Table 3.

Table 3

Efficiencies of the FCHEV with different hybrid ratios under four running conditions.

\begin{tabular}{lcccc}
\hline \multirow{2}{*}{$\begin{array}{l}\text { Hybrid } \\
\text { ratio }\end{array}$} & NEDC & UDDS & HWEFT & CONSTANT_60 \\
\hline 0.25 & 5.8 & 6.2 & 6.5 & 6.5 \\
0.3 & 5.7 & 6.1 & 6.7 & 6.7 \\
0.4 & 5.3 & 5.8 & 7.0 & 6.9 \\
0.5 & 5.5 & 6.1 & 7.5 & 7.4 \\
0.6 & 5.7 & 6.3 & 8.0 & 8.0 \\
0.7 & 6.0 & 6.6 & 8.4 & 8.5 \\
0.8 & 6.3 & 7.0 & 9.0 & 8.9 \\
0.9 & 6.6 & 8.0 & 9.8 & 9.7 \\
1.0 & 6.8 & 8.9 & 10.5 & 10.4 \\
\hline
\end{tabular}


The results in Fig. 6 clearly show that the equivalent fuel consumption per $100 \mathrm{~km}$ for our FCHEV increases continuously with increasing hybrid ratio for HWEFT and CONSTANT_60. For NEDC and UDDS, the equivalent oil consumption per $100 \mathrm{~km}$ drops significantly and then increases with increasing hybrid ratio.

We analyzed the average working efficiency of the fuel cell at each hybrid ratio under different working conditions to understand the mechanism of the above result. The average working efficiency of fuel cells is determined by the average power required by the working conditions. The average efficiency of the fuel cell as a function of the hybrid ratio is shown in Fig. 7, which has the opposite trend to the fuel consumption per $100 \mathrm{~km}$ for all the different test modes.

The average working efficiency of the fuel cell has a strong positive correlation with the equivalent oil consumption per $100 \mathrm{~km}$. The working efficiency of the fuel cell decreases continuously, while the equivalent oil consumption per $100 \mathrm{~km}$ increases continuously with increasing hybrid ratio for HWEFT and CONSTANT_60. However, for NEDC and UDDS, the working efficiency of the fuel cell increases slightly and then decreases above the hybrid ratio of 0.4 . The equivalent oil consumption per $100 \mathrm{~km}$ has the opposite trend to the working efficiency. Thus, it is necessary to maintain working conditions that ensure a high efficiency for the FCHEV system. The following analysis is based on the results in Figs. 6 and 7 .

When a vehicle starts, the rechargeable batteries provide the power $P_{\text {req }}$ required for driving and the additional load $P_{a c c}$. Thus, the output power of the batteries $P_{b a t}$ is

$$
P_{b a t}=P_{r e q}+P_{a c c}
$$

When the fuel cells are warmed up to the operating temperature, it is determined from the power requirements whether to start the fuel cells. When the power required by the system is

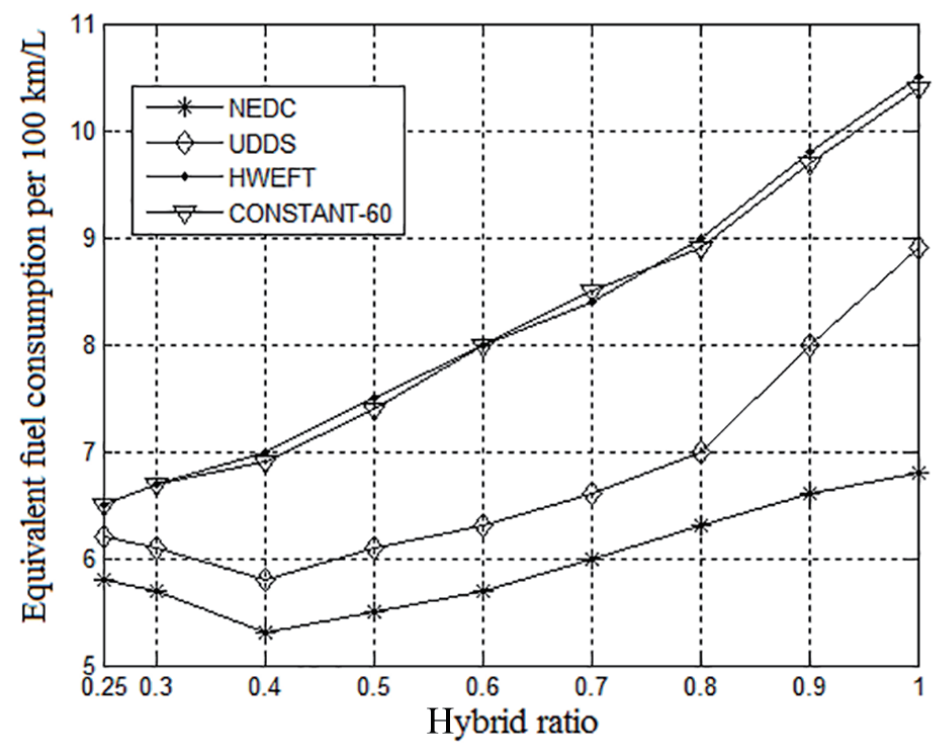

Fig. 6. Relationship between equivalent fuel consumption per $100 \mathrm{~km}$ and hybrid ratio. 


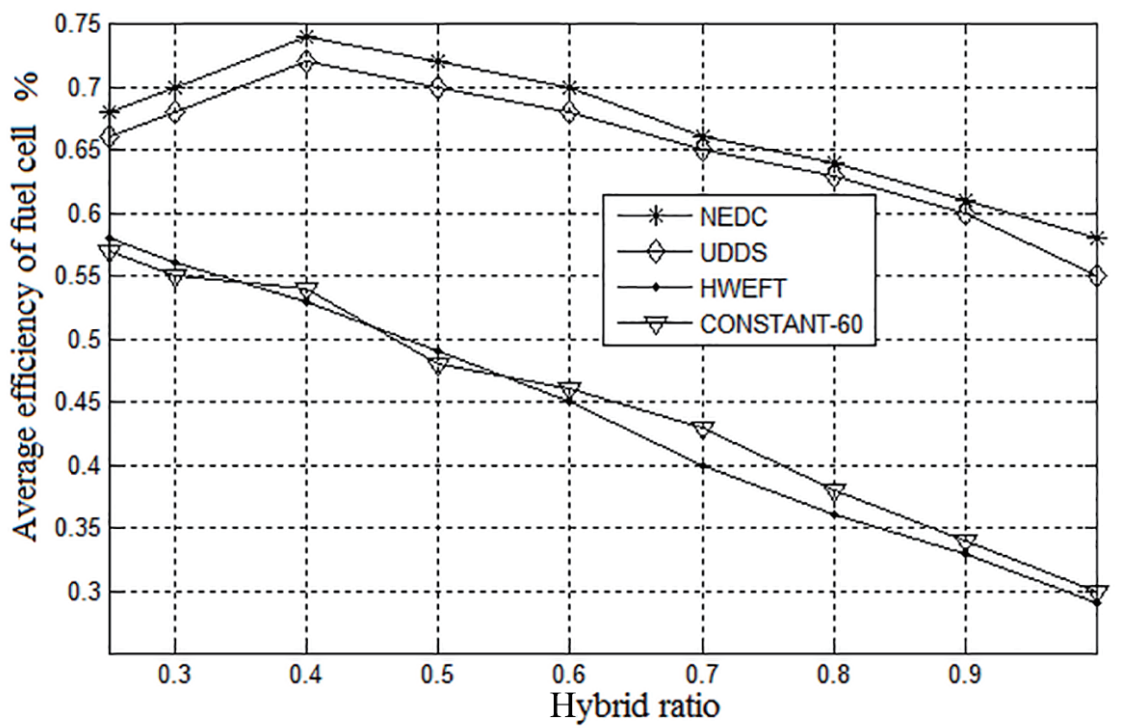

Fig. 7. Variation in average efficiency of fuel cell with the hybrid ratio.

less than the minimum power provided by the fuel cells, the batteries must still supply power separately.

For normal driving conditions, the power required by the vehicle is between the minimum and maximum powers of the fuel cells. Thus, the fuel cells are turned on and the batteries do not use their power on the drive system. At this time, the fuel cells supply the electrical power not only for driving but also for the additional load. To maintain the SOC of the batteries within a certain range [the target value is $\left(S O C_{\max }+S O C_{\min }\right) / 2$ ], the fuel cells charge the batteries. Therefore, the power required by the fuel cell is

$$
P_{f c}=P_{r e q}+P_{a c c}+P_{S O C}
$$

where $P_{S O C}=\frac{\left(S O C_{\max }+S O C_{\min }\right) / 2-S O C}{\left(S O C_{\max }-S O C_{\min }\right) / 2} \times P_{c s_{-} c h g}$. Here, $P_{c s_{-} c h g}$ is the power when $S O C=S O C_{\min }$. When $S O C \geq S O C_{\max }$, the fuel cell stops charging the batteries and only provides additional driving power and load power.

When the vehicle accelerates or climbs, the required power exceeds the maximum power of the fuel cell, and the batteries add their power to the supply circuit. When the batteries supply power, the efficiency of the entire system improves. The batteries provide the required supplementary power, which is added to $P_{b a t}$. Therefore, the total power for the drive system is

$$
P_{f c_{-} \max }+P_{b a t}=P_{r e q}+P_{a c c},
$$

where $P_{f_{-} \text {max }}$ is the maximum power provided only by the fuel cells. 
Thus, when the hybrid ratio is less than 0.4 , the rechargeable batteries supply more power to give a higher efficiency for starting and accelerating to a certain speed. Then, the fuel cells start to supply more power than the rechargeable batteries, lowering the efficiency and increasing the hybrid ratio. When the fuel cells supply power alone, at a hybrid ratio of 1 , all the power is used to drive the vehicle as well as charge the batteries, which lowers the average efficiency of the fuel cells. This is why NEDC and UDDS have an inverted V-shaped curve for the average working efficiency of the fuel cells as a function of the hybrid ratio.

The efficiency decreases continuously with increasing hybrid ratio for HWEFT and CONSTANT_60. This implies that a larger power from the fuel cells is required for these working conditions than for NEDC and UDDS. This reduces the efficiency of the fuel cells and increases the equivalent fuel consumption. In brief, it is inferred that the hybrid ratio of 0.4 is optimal for the model FCHEV, giving the lowest equivalent fuel consumption for various working conditions.

\section{Conclusion}

In this study, we obtained the optimal hybrid ratio and system parameters of an FCHEV with a PEM FC and Li-ion rechargeable batteries as its hybrid power sources. We selected basic parameters of the model FCHEV, studied the optimization of its system, and obtained suitable parameters. By modeling the FCHEV power system with the ADVISOR simulator, we carried out simulation tests of the model vehicle under different working conditions to obtain results for the power performance and fuel economy. The main conclusions of this study are as follows:

1. We chose a PEM FC for this study and determined the efficiency and load rate compared with those of an internal combustion engine. The parameter design for the power of fuel cells in this study gives the maximum output power of the fuel cells as $70 \mathrm{~kW}$. The relevant parameters for the $\mathrm{AC}$ induction motors in this study are a rated power of $60 \mathrm{~kW}$, a maximum power of $120 \mathrm{~kW}$, a rated torque of $355 \mathrm{~N} \cdot \mathrm{m}$, a maximum torque of $710 \mathrm{~N} \cdot \mathrm{m}$, a maximum speed of $4000 \mathrm{r} / \mathrm{min}$, and a rated speed of $1600 \mathrm{r} / \mathrm{min}$. The power of the batteries was $50 \mathrm{~kW}$ for the output power of the motor. On the basis of these parameters, the design and selection of critical components of the fuel cell power system were suggested.

2. We employed the modified parameters of the power system and the control strategies to model and simulate the FCHEV using ADVISOR in a UDDS test. The results show that the driving speed was the same as the actual speed, and the maximum speed of the FCHEV was $127.4 \mathrm{~km} / \mathrm{h}$. The maximum grade ability was $19.1 \%$ when the speed was $20 \mathrm{~km} / \mathrm{h}$. Moreover, the fuel consumption per $100 \mathrm{~km}$ over a traveling distance of $11.8 \mathrm{~km}$ under the UDDS conditions was $93.3 \times 10^{-2} \mathrm{~L} / \mathrm{km}$, which was equivalent to the fuel consumption of about $6.3 \times 10^{-2} \mathrm{~L} / \mathrm{km}$ for a traditional internal combustion engine vehicle. Therefore, the model FCHEV appears to meet the requirements for the dynamic performance and fuel economy of passenger cars.

3. We analyzed the efficiencies of the model vehicle with different hybrid ratios under four different test modes: NEDC, UDDS, HWEFT, and CONSTANT_60. The optimal hybrid ratio was 0.4 when the power of the fuel cells was about $50 \mathrm{~kW}$, and the power of the rechargeable batteries was $70 \mathrm{~kW}$. 
We believe that these optimization results provide guidance for the design of actual FCHEV vehicles with fuel cells and rechargeable batteries.

\section{Acknowledgments}

We gratefully acknowledge the financial support of this research by the National Natural Science Foundation of China (Grant No. 51505241), the Natural Science Foundation of Fujian province (Grant No. 2018J01509), the Key Laboratory of Intelligent Ecotourism and Leisure Agriculture in Fujian Province, and the Digital Fujian Institute of Rehabilitation and Nursing for the Elderly.

\section{References}

1 S. A. Bagloee, M. Tavana, and M. Asadi: J. Mod. Transp. 24 (2016) 284. https://doi.org/10.1007/s40534-0160117-3

2 T. Hua, R Ahluwalia, and L. Eudy: J. Power Sources 269 (2014) 975. https://doi.org/10.1016/ j.jpowsour.2014.06.055

3 A. Burdzik, M. Stähler, and I. Friedrich: J. Coat. Technol. Res. 19 (2018) 1. https://doi.org/10.1007/s11998-0180074-3

4 Z. Yu, Z. Dan, and K. Zhang: Microsyst. Technol. 23 (2017) 3257. https://doi.org/10.1007/s00542-016-3122-x

5 S. Li, J. Yuan, and G. Xie: Int. J. Hydrogen Energy 43 (2018) 8451. https://doi.org/10.1016/j.ijhydene.2018.03.106

6 O. S. Popel, A. B. Tarasenko, and S. P. Filippov: Therm. Eng. 65 (2018) 859. https://doi.org/10.1134/ S0040601518120078

7 J. An, N. Li, and L. Wan: Water Res. 123 (2017) 369. https://doi.org/10.1016/j.watres.2017.06.087

8 L. Minglin, Z. Weirong, P. Haosheng, and L. Lianfeng: Jpn. J. Appl. Phys. 58 (2019) 055003. https://doi. org/10.7567/1347-4065/ab0646

9 W. Cheng, Q. Ouyangi, and Z. Xiaohui: Shanghai Auto. 3 (2008) 4. https://doi.org/ CNKI:SUN:SHQC.0.2008-03-004

10 J. S. Cao: Appl. Mech. Mater. 644 (2014) 446. https://doi.org/10.4028/www.scientific.net/AMM.644-650.446

11 A. J. Appleby and J. Twidell: Philos. Trans. R. Soc. London, Ser. A. 354 (1996) 36. https://doi.org/10.1098/ rsta.1996.0073

12 L. Horrein, A. Bouscayrol, and Y. Cheng: Energy Convers. Manage. 129 (2016) 250. https://oi.org/10.1016/ j.enconman.2016.10.030

13 P. Wang and H. Xiaofeng: Shanghai Auto. 3 (2010) 7. https://doi.org/CNKI:SUN:SHQC.0.2010-03-003

14 D. Suman: J. Ind. Eng. Chem 20 (2014) 1148. https://doi.org/10.1016/j.jiec.2013.07.037

15 M. Nishibori, W. Shin, and N. Izu: J. Hydrogen Energy. 34 (2009) 2834. https://doi.org/10.1016/ j.ijhydene.2009.01.027

16 M. Kimura and N. Takashima: Sens. Mater. 23 (2011) 419. https://doi.org/10.18494/SAM.2011.742

17 L. Tribioli, R. Cozzolino, and D. Chiappini: Appl. Eng. 184 (2016) 140. https://doi.org/10.1016/ j.apenergy.2016.10.015

18 B. Qian: New Energy Vehicles and New Energy Storage Batteries and Hot Spot Conversion Technology, Eds. B. Qin (Science Press, Beijing, 2010) Chap. 3.

19 Y. Guezennec, T. Y. Choi, and G. Paganelli: Proc. 2003 Am. Control Conf. (IEEE, 2003). https://doi. org/10.1109/ACC.2003.1243377

20 M. J. Kim and H. Peng: J. Power Sources 165 (2007). https://doi.org/10.1016/j.jpowsour.2006.12.038

21 P. Atwood, S. Gurski, and D. J. Nelson: Proc. 2001 SAE Congress (SAE, 2001). https://doi.org/10.471/2001-010236.

22 Z. Tao, S. Ke, and Z. Tong: Mechatronics 7 (2015) 11. https://doi.org/10.16413/j.cnki.issn.1007080x.2015.07.003

23 WIKIPEDIA: https://en.wikipedia.org/wiki/New European_Driving Cycle (accessed March 2020).

24 WIKIPEDIA: https://en.wikipedia.org/wiki/FTP-75 (accessed March 2020).

25 Dieselnet: https://dieselnet.com/standards/cycles/hwfet.php (accessed March 2020). 